\title{
An analysis of writer's performance, resources, and idea generation processes: the case of Filipino engineering students
}

\author{
Leah E Gustilo
}

\author{
Correspondence: \\ leah.gustilo@dlsu.edu.ph \\ Department of English and Applied \\ Linguistics, De La Salle University, \\ Manila, 2401 Taft Ave., Manila 1004, \\ Philippines
}

\begin{abstract}
The purpose of the pilot study, which is a part of a larger project on ESL writing involving freshmen college students in the Philippines, is to explore the relationship between writer's performance, writer's resources, and writer's idea generation process. To measure the writer's performance, diagnostic essays of 85 Filipino freshmen engineering students were evaluated based on Gustilo's (2011) modified holistic scoring guide. To measure writer's resources, tests on linguistic knowledge and topic familiarity and a survey questionnaire on writing background were administered to the same students. To measure writer's idea generation process while composing, a Likert Scale questionnaire based on Chenoweth and Hayes 2001 and 2003 models was designed and administered to the students after their diagnostic essay task. Pearson product moment correlation was used to test for significant relationships. Discourse completion task (DCT) was administered to confirm the results gathered through quantitative method. Findings partly confirm the findings of previous studies. Writer's performance is correlated with all the variables under study except for spelling test.
\end{abstract}

Keywords: ESL writing, ESL assessment, Cognitive resources, Writing performance, Filipino linguistic knowledge

\section{Background}

Writing teachers and researchers have always set their teaching and research lenses on the variables that describe successful writing vis-à-vis unsuccessful writing (Flower \& Hayes, 1980, 1981; Ferrari et al. 1998; Zhang, 2008; McNamara et al. 2009). Because of this preoccupation, a plethora of research has been undertaken as regards composing (Perl, 1978; Pianko, 1979; Flavel, 1979; Flower \& Hayes, 1980; Flower \& Hayes, 1981; Devine et al., 1993; Victori, 1995, 1997; Chenoweth \& Hayes, 2001 and Chenoweth \& Hayes, 2003; Gustilo, 2010, 2011). One area of research that dominates the literature is the one underpinned by the cognitive process model research popularized by Flower and Hayes $(1980,1981)$ and those that aligned their studies on their theoretical models (Bosher, 1998; Myles, 2002; Zhai, 2008; Galbraith, 2009). Most of these studies used think-aloud-protocol as their main method of data collection to describe the strategies and writing processes of writers (Perl, 1978; Pianko, 1979; Flavel, 1979; Flower \& Hayes, 1980; Flower \& Hayes, 1981; Raimes, 1985; Cumming, 1989; Whalen, 1993; 
Devine et al., 1993; Victori, 1995, 1997). Researchers all agree that the writer's processes involved while composing written tasks can shed light in differentiating the characteristics of skilled writers from poor writers.

The main aim of the present pilot study is to assess the writing performance of Filipino college freshmen engineering students and to relate this performance to the other factors that impact writing performance within the cognitive process model framework of Chenoweth and Hayes $(2001,2003)$.

\section{Literature review}

The literature on writing examines the cognitive skills or composing processes employed by writers in the process of producing their texts (Tillema et al., 2011; Coirier \& Favart, 2002; Karagiannopoulou, 2006; Deane et al., 2008). Writers activate various strategies as they engage in different writing subprocesses, which include planning, translating/drafting, and post-writing (Humes, 1983; Gustilo, 2010). Examining the processes utilized by language learners in composing helps identify how these processes function in writing among writers. More importantly, describing these processes has helped characterize the differences and/or similarities between good and poor writers. Flower and Hayes (1980) characterized good writers as having the ability to respond to all aspects of the rhetorical problem, while poor writers respond to "features and conventions of a written text" (p. 93). Good writers represent the problem in more breadth and depth than did the poor writers. Humes (1983) claimed that planning separates good and bad writers as good writers spend more time in global planning than poor writers do. Additionally, good writers review and revise their texts on high levelelements of writing such as concerns about style, audience, and tone. Castro (2005) explained that expert writers had more pre-writing activities, more generated ideas, more organizational decisions, more retrieved ideas, and more evaluations before writing down their notes than did the novice writers. Similarly, Becker (2006) claimed that novice writers possessed a grim view of rewriting-viewing it as punitive; while expert or skilled writers viewed rewriting as an opportunity to discover ways to improve the quality of the text. Gustilo (2010) concluded that proficient writers, whether they plan or not during the pre-writing stage, may have the same results.

Cognitive-based writing research and assessment have successfully identified the variables that are at work while writing, have informed writing assessment frameworks, have refined and redeveloped the cognitive-based writing models evolved in the 80s and 90s, and have suggested instruction techniques tailored to the needs of the writers (Becker, 2006). However, one of the limitations of the early models of cognitive research is that they mostly involved laboratory case studies involving few participants, usually limited to 1 to 20 participants, using interviews and think-aloud protocols-a method which asks students to compose aloud while writing-which is regarded by many us unnatural because, in actual writing, writers do not compose aloud (Humes, 1983). The present pilot study is unique in that it will involve 85 participants writing in a naturalistic situation in a class.

Most of the early studies on cognitive process framework focused on the processes while composing. Recent research, however, have focused not only on composing processes but also on the factors in the writers' long term memory, (which Chenoweth \& Hayes 2001 and 2003 call as the resource level) such as (meta)cognitive knowledge and 
linguistic resources (Schoonen et al., 2003; Almasadani, 2010), which writers call upon in producing their texts. For instance, Sasaki and Hirose (1996) recognized that writing performance is dependent on the interplay of several factors such as L1 writing ability, L2 proficiency, L2 metaknowledge, and prior L2 writing experience/education. Among the three variables that they quantitatively measured, L2 proficiency accounted for the biggest portion of L2 performance variance. Based on their qualitative analysis, Sasaki and Hirose claimed that L2 writing background, as measured by L1 and L2 writing experience and writing confidence, is a potential explanatory variable for writing ability. The present study would like to confirm this by measuring writing background using quantitative method.

Drawing on proficiency and cognitive models from previous studies, Schoonen et al. (2003) also recognized that different components of knowledge and skills are fundamentally relevant to writer's performance. Exploring the relative contribution of linguistic knowledge (grammar, vocabulary and orthography) and metacognitive knowledge at the writer's resource level and the speed of processing at the writer's process level to writing proficiency across L1 and L1, they collected data from 281 grade 8 students using writing tasks to measure L1 and L2 proficiency; tests on grammar, vocabulary, orthography, and metaknowledge to assess the writer's resources in the memory; and speed of lexical retrieval and sentence building to measure the writers' fluency in accessing linguistic knowledge. Their study claimed that L2 linguistic tests highly correlated with L2 writing proficiency than L1 linguistic tests with L1 writing proficiency did. Also, the comparison of the contributions of knowledge tests (linguistic and metaknowledge) vis-a-vis speed of processing, showed that speed of processing, although correlated to writing proficiency, had almost no unique contribution in predicting writing proficiency in L1 and L2.

\section{Theoretical framework}

Chenoweth and Hayes $(2001,2003)$ have developed a more detailed process involved in text production, which captures the interplay between knowledge stored in the memory and the processes that are at work in accessing these knowledge. The model includes three levels: the control level, the resource level, and the process level.

The control level includes "the task goals and a set of productions that govern the interactions among the processes" (p. 87). The resource level as explained by Chenoweth and Hayes $(2001,2003)$ includes the long-term memory, the working memory, and other general purpose processes (e.g. process of reading) that the control level and process level can manipulate. Linguistic and metaknowledge are part of the resource level (Schoonen et al., 2003). In the present study, the relationships between these different resources of writers (linguistic knowledge, topical knowledge, writing background) and writing performance will be quantitatively measured.

The process level is divided into components. The external component includes the audience for the writing task, the written text, and task materials used to draft the text such as dictionaries and peer's notes. This is equivalent to task environment in Hayes' 1996 model. The internal component includes four processes: the proposer, which produces pre-linguistic ideas to be expressed; the translator, which converts pre-linguistic ideas into strings of "language with appropriate word order and grammar" (p.84); the transcriber, which translates linguistic strings into text; and the reviser, which evaluates and revises both the pre-linguistic ideas and written language. The present study will 
examine only the first internal component, the proposer, by measuring the idea generation processes of students while composing.

In sum, in producing a text, any of the internal processes at the process level may activate long-term memory, working memory, or critical reading in the resource level in order to complete the goals set by the control level.

\section{Research questions and hypotheses}

In consideration of the above review of literature and theoretical framework, the present pilot study aimed at examining the following questions:

1. Is there any relationship between Filipino engineering students' writing performance and their topic familiarity?

2. Is there any relationship between their writing performance and their writing background?

3. Is there any relationship between their writing performance and their idea generation processes?

4. Is there any relationship between their writing performance and their linguistic knowledge (spelling, grammar and vocabulary).

The study tested the following null hypotheses:

1. There is no relationship between Filipino engineering students' writing performance and their topic familiarity.

2. There is no relationship between their writing performance and their writing background.

3. There is no relationship between their writing performance and their idea generation processes.

4. There is no relationship between their writing performance and their linguistic knowledge (spelling, grammar, and vocabulary).

\section{Significance of the study}

The findings of the present study can help writing teachers assess their teaching strategies in relation to the factors that underlie successful writing, inform the students as to what characterizes successful and unsuccessful writing, and lead to generalizations pertinent to writing research, writing instruction, and writing assessment.

\section{Methods}

\section{Participants}

The pilot study involved three sections of Filipino freshmen engineering students in one of the leading institutions in the country. Their ages ranged from 16-18 years. The participants were enrolled in an English course (ENGLCOM), the first of the three required English courses in their program.

\section{Procedure}

\section{Content validation, pre-testing, and reliability test}

The idea generation text production scale and writing background scale used in this pilot study underwent content validation, pre-testing, and reliability test. First, these instruments were presented to three content validators, faculty members who have been either teaching 
writing for a long time or doing research on ESL writing. Their comments have been helpful in revising the scales. Then participative pre-testing was made, in which students were asked at the end of a pilot survey whether they had encountered difficulty in answering the questions and whether they have suggestions to improve the scale. The pre-testing of survey scales was administered to a different set of respondents (40 students) on the first day of the term after they had written their diagnostic essay test.

Using SPSS, the survey replies on the scales were analyzed for their reliability. The cronbach alpha computed for writing background was $\mathrm{r} .854$, meaning that there is a strong internal consistency among the scale items and that the respondents who tended to select high scores for one item also tended to report high scores for the other items. The computed cronbach apha for idea generation process is $r=.708$.

Likewise, the topic familiarity test was presented to content validators prior to the testing date to ascertain whether the items were within the scope of the topic under study and whether or not the items were understandable and within the level of the students being tested. During the participative pre-testing, students were also asked whether the questions they encountered were too difficult for them or whether they expected to encounter other questions that were not in the test. Majority of the respondents affirmed that the topic familiarity test was understandable and that all the questions they expected to encounter were all in the test.

\section{Administration of tests and writing task}

The writing task and tests administered to the students during the first two weeks of the term and at the end of the term included the following:

\section{Diagnostic essay test}

On the first week of the class, the students were asked to write a persuasive essay about the implementation of K-12 in the Philippines, a topic which had been a focus of debate among school and government authorities. The study used the following prompt:

In 30-45 minutes, write a persuasive essay on the topic "K-12 Education in the Philippines." State whether or not you are in favor of the implementation of K-12 in the Philippines. Then give at least three reasons for your position/claim.

All essays were holistically rated by me and two other raters using Gustilo's (2011) modified six-point scale scoring guide-a rubric she used in her previous study in assessing 150 essays from five universities in the Philippines. We did practice rating, rating a sample of essays on our own. After which, we met together to see if we had disparate or similar scores. The two other raters unanimously affirmed that the rubric was a very good instrument in assessing essay performance because the descriptors could account for the different elements usually focused on in assessing essays in the ESL context (See Additional file 1: Appendix).

\section{Topic familiarity test}

Prior to the administration of the essay task, the students were asked to accomplish a topic familiarity test. This test measured their prior knowledge on the subject of the essay. 
Questions such as the definition of K-12, objectives of the implementation of K-12, facts concerning countries that implemented $\mathrm{K}-12$, and the like were included in the test.

\section{Text production survey}

After the writing task, students accomplished a survey regarding the different processes involved in writing. The scale has 25 items covering the four internal components of Chenoweth and Hayes's $(2001,2003)$ model. The present study reported only the proposer component or the idea generation process, which has 12 items (See Additional file 1: Appendix).

\section{Writing background survey}

Drawing on Sasaki and Hirose (1996), I designed a writing background scale, which covers questions about the skills students had developed in high school, the writing situations they had been exposed to (school-related and personal writing), and their confidence level based on their writing background. The survey was administered to the students after they had written the diagnostic essay.

\section{Linguistic knowledge test}

On the second week of the term, three tests were administered to measure students' linguistic knowledge: grammar test, vocabulary test, and spelling test.

The grammar test consisted of 72 items from Azar (2002) and Chapman (1992). The test required the students to call on their knowledge in identifying parts of speech, making verbs agree with the sentence, supplying the correct form of the verb, using correct pronoun and article usage, and identifying fragment and run-on sentences (See Additional file 1: Appendix for sample questions).

The vocabulary test consisted of 60 multiple choice items. The items in Part I of the test were taken from the reading selections of an English communication textbook for freshmen college students (Cusipag et al., 2006). The target word was italicized and was given a linguistic context through a sentence. Part II vocabulary items were taken from Alan Beale's (2003) Core Dictionary, a compilation of words from three ESL dictionaries (See Additional file 1: Appendix for sample items).

The spelling test consisted of 85 items which were taken from Alan Beale's (2003) Core Dictionary. The respondents had to choose the correct spelling from three choices written in three columns (See Additional file 1: Appendix for sample items).

\section{Reflective survey}

Before the end of the course, the students were given an opportunity to be involved in the assessment of their writing performance and the factors that contributed to their success or failure in writing the diagnostic essay. Their rated diagnostic essays were returned to them, with the grades appearing on the upper right part of the paper. They were instructed to reflect on their essays as to whether they did well or poorly in relation to the rates they obtained. Then they accomplished a Discourse 
Completion Task (DCT) requiring them to write down their thoughts on the following questions:

1. Do you believe that topic familiarity or your knowledge about the topic contributed to the success of your diagnostic essay and helped you get a high grade in your essay? Why or why not?

2. Do you believe that your writing background contributed to your performance in writing the diagnostic essay? Why or why not?

3. Do you believe that your text production process such as idea generation while composing played a role in your writing performance? Why or why not?

4. Do you believe that your linguistic knowledge such as grammar usage, vocabulary, and spelling has a bearing in your success in writing the diagnostic essay? Why or why not?

\section{Data analysis}

1. Survey replies were typed in excel program. Then the data were entered in SPSS version 19 for reliability and correlation analyses.

2. Essay scores from each rater were compared. The study adopted the majority rulewhich means that if two raters out of three gave a similar score, the same will be the score of the essay. On the other hand, if the three raters have no agreement, their scores are averaged, and the resulting average score is the final essay score.

3. The qualitative survey replies of the respondents were read and categorized into themes. Frequencies of yes and no were tallied.

\section{Results}

The first section presents the quantitative results gathered through surveys and linguistic tests. This is followed by the results on the qualitative data (Discourse Completion Task).

\section{Research question 1}

To answer the first question, "Is there any relationship between Filipino writing performance and their topic familiarity?" Pearson product moment correlation was performed. Cohen's (1988) classification of correlation guided the interpretation of statistical results. The study considered $r=.10$ to .29 as having small correlation, $r=.30$ to .49 as having medium correlation, and $\mathrm{r}=.50$ to 100 as strong correlation. The first statistical analysis yielded a strong positive relationship between essay performance and topic knowledge, $\mathrm{r}=.79, \mathrm{~N}=60, . p<.01$, indicating that high levels of writing performance are associated with high scores in topic knowledge as shown in Table 1 below.

Table 1 Pearson product moment correlations between topic knowledge and essay score

\begin{tabular}{llll}
\hline & & Topic Familiarity & Essay \\
\hline \multirow{2}{*}{ topic familiarity } & Pearson Correlation & 1 & $.795^{* *}$ \\
\cline { 2 - 4 } & Sig. (2-tailed) & & .000 \\
\cline { 2 - 4 } & $\mathrm{N}$ & 85 & 85 \\
\hline \multirow{2}{*}{ Essay } & Pearson Correlation & $.795^{* *}$ & 1 \\
\cline { 2 - 4 } & Sig. (2-tailed) & .000 & 85 \\
\cline { 2 - 4 } & $\mathrm{N}$ & 85 & \\
\hline
\end{tabular}

**. Correlation is significant at the 0.01 level (2-tailed). 


\section{Research question 2}

As regards the second question, "Is there any relationship between Filipino writing performance and their writing background?" the same statistical procedure was used, Pearson product moment correlation analysis. The results in Table 2 below show the increases in essay scores is significantly related to the increases in the writing background scores of the students: $\mathrm{r}=.32, \mathrm{~N}=60, \mathrm{p}<.01$.

\section{Research question 3}

The third analysis gave light on the question: "Is there any relationship between Filipino writing performance and their idea generation processes?" Pearson product moment correlation analysis revealed that there is a strong positive relationship between text production process, which is idea generation, and writing performance: $r=.64, \mathrm{~N}=85$, $\mathrm{p}<.01$., as shown in Table 3 below.

\section{Research question 4}

The last question, "Is there any relationship between Filipino writing performance and their linguistic knowledge?" requires that the students' scores in spelling, grammar, and vocabulary be correlated with essay score. As shown in Table 4 below, vocabulary knowledge is significantly related with essay score $(\mathrm{r}=.57, \mathrm{p}<.01)$. Likewise, grammar knowledge is significantly related with writing performance $(\mathrm{r}=.25, \mathrm{p} .<.05)$. Spelling, however, is found to have been no significant relationship with writing score.

Results of the Discourse completion task (DCT) confirmed the relationship between writers' performance and linguistic knowledge, topic knowledge, and idea generation process. The questions in the DCT and the sample replies of the respondents are discussed below.

1. Do you believe that topic familiarity or your knowledge about the topic contributed to the success of your diagnostic essay and helped you get a high grade in your essay? Why or why not?

All respondents except one replied with an affirmative on this question. They indicated that topic familiarity enabled them to provide more information and enough supporting details-elements that are considered to be important factors in assessing essays. In addition, topic familiarity mattered in the generation of ideas. Here are some of their replies:

Yes, because you have more knowledge about the topic and you have more information to add in your supporting details. (Respondent 34)

Table 2 Pearson poduct moment correlations between essay scores and writing background

\begin{tabular}{llll}
\hline \multirow{2}{*}{ Writing Background } & & Writing background & Essay score \\
\cline { 2 - 4 } & Pearson Correlation & 1 & $.328^{* *}$ \\
\cline { 2 - 4 } & $\mathrm{N}$ & 85 & .002 \\
\hline Essay Score & Pearson Correlation & $.328^{* *}$ & 85 \\
\cline { 2 - 4 } & Sig. (2-tailed) & .002 & 1 \\
\cline { 2 - 4 } & $\mathrm{N}$ & 85 & 85 \\
\hline
\end{tabular}

**. Correlation is significant at the 0.01 level (2-tailed). 
Table 3 Pearson product moment correlations between idea generation process and essay scores

\begin{tabular}{llll}
\hline & & Idea generation processes & Essay scores \\
\hline Idea generation processes & Pearson Correlation & 1 & $.639^{* *}$ \\
\cline { 2 - 4 } & Sig. (2-tailed) & & .000 \\
\cline { 2 - 4 } & $\mathrm{N}$ & 86 & 85 \\
\hline Essay scores & Pearson Correlation & $.639^{* *}$ & 1 \\
\cline { 2 - 4 } & Sig. (2-tailed) & .000 & 85 \\
\cline { 2 - 4 } & $\mathrm{N}$ & 85 & \\
\hline
\end{tabular}

**. Correlation is significant at the 0.01 level (2-tailed).

Yes, because knowing the background of the topic can bring depth to the essay.

(Respondent 2)

Yes, it can affect mainly because I would not have enough supporting details for my topic sentence. (Respondent 4)

Yes. Because if you are familiar about the topic you can write many supporting details that are necessary in your essay. (Respondent 23)

Yes, because when you are familiar with a topic, it is easier to develop a paragraph because of the knowledge you possess. Also, it would not be hard to think of ideas. (Respondent 8)

Yes, because when you know more about the topic, there would be more ideas and the quality of the essay is efficient. (Respondent 9)

Yes, because the more familiar you are, the easier to think about ideas for your essay. (Respondent 40)

2. Do you believe that your high school writing background contributed to your performance in writing the diagnostic essay? Why or why not?

Table 4 Pearson product moment correlations between linguistic knowledge measures and essay scores

\begin{tabular}{|c|c|c|c|c|c|}
\hline & & Vocabulary & Spelling & Grammar & Essay score \\
\hline \multirow[t]{3}{*}{ Vocabulary } & Pearson Correlation & 1 & $.228^{*}$ & $.302^{* *}$ & $.574^{* *}$ \\
\hline & Sig. (2-tailed) & & .036 & .005 & .000 \\
\hline & $\mathrm{N}$ & 85 & 85 & 85 & 85 \\
\hline \multirow[t]{3}{*}{ Spelling } & Pearson Correlation & $.228^{*}$ & 1 & .096 & .149 \\
\hline & Sig. (2-tailed) & .036 & & .382 & .172 \\
\hline & $\mathrm{N}$ & 85 & 85 & 85 & 85 \\
\hline \multirow[t]{3}{*}{ Grammar } & Pearson Correlation & $.302^{* *}$ & .096 & 1 & $.252^{*}$ \\
\hline & Sig. (2-tailed) & .005 & .382 & & .020 \\
\hline & $\mathrm{N}$ & 85 & 85 & 85 & 85 \\
\hline \multirow[t]{3}{*}{ essay score } & Pearson Correlation & $.574^{* *}$ & .149 & $.252^{*}$ & 1 \\
\hline & Sig. (2-tailed) & .000 & .172 & .020 & \\
\hline & $\mathrm{N}$ & 85 & 85 & 85 & 85 \\
\hline
\end{tabular}

*. Correlation is significant at the 0.05 level (2-tailed).

**. Correlation is significant at the 0.01 level (2-tailed). 
In this part of the survey, $21 \%$ of the respondents replied that their high school writing background had no effect on their present writing performance. Here are some of the reasons for their claim:

My background had no contribution for my present performance for I was poorly oriented in my high school writing and yet I did not perform poorly in my essay. (Respondent 9)

In a way, no because I have poor background in writing, but I am not doing poorly. (Respondent 23)

I think it's not because I was a bad writer in high school. (Respondent 13)

I don't think so. I find college writing very different from high school writing. In fact, I am using different writing strategies this college compared when I was in high school. Besides, I am not really a good writer during my high school years but I got a good grade in my diagnostic and other essays. This proves that writing background does not matter. (Respondent 17)

On the other hand, 79\% acknowledged writing background as having a part in their success in writing their diagnostic essay; they believed that high school writing experience gave them a foundation for writing. Here are some of their reasons for thinking that their writing background had to do with their present writing performance:

Yes, because having good knowledge in a topic can still be ruined by a bad background in writing. On the other hand, a good background in writing can be the saving grace for someone with limited knowledge of a topic. (Respondent 33)

Of course, because high school days were the days that I learned to write an essay and to believe that I can write them on my own. It gave me confidence with my English writing. (Respondent 39)

Yes. I believe that my background in writing contributed to my success in writing essays because you know how it works and thus making it easier for you. (Respondent 29)

3. Do you believe that your text production processes such as idea generation while composing played a role in your writing performance? Why or why not?

As regards the role of text production processes such as idea generation, the respondents had a unanimous answer. They reported that the processes they had activated while writing the essay had a direct relationship with the product of their essay. Here are what they had to say on this claim:

Yes, if you generated ideas really well, then you will come up with a very good essay. (Respondent 16) 
Yes, because it affects the delivery of ideas. (Respondent 36)

Yes it does. This text production process greatly helps the writer. The process makes the writing flow much easier. (Respondent 38)

Yes, specially if the writing of the essay is time-bound. (Respondent 27)

4. Do you believe that your linguistic knowledge such as grammar usage, vocabulary, and spelling has a bearing in your success in writing the diagnostic essay? Why or why not?

To this question, all the respondents have a unanimous affirmative reply, indicating that the content of the message is dependent on the linguistic structures they form. The respondents considered linguistic knowledge as an important factor in the creation of meaning during the text production, thereby affecting the comprehensibility of the message being transmitted.

I believe that my linguistic knowledge play the biggest role in writing an effective essay because I will be able to better express myself. (Respondent 2)

Yes. Linguistic knowledge greatly affects the quality of an essay because it will affect on how the reader comprehends your essay. Having the improper linguistic knowledge will give the readers a difficult time in understanding your essay. (Respondent 28)

Yes because these are very important in English writing. Wrong grammar and spelling and wrong vocabulary use can alter the meaning of the message. (Respondent 12)

Yes, because my linguistic knowledge affects the effectiveness of the delivery of the ideas I want to convey in my essays. (Respondent 36)

I believe that wide vocabulary and being able to follow grammatical rules will greatly affect the quality of an essay. The essay would not be effective if there are flaws on the grammar or has faults on spelling. (Respondent 25)

\section{Discussion}

Going back to the research questions examined in this pilot study, as regards question one, the study rejects the first null hypothesis and accepts the alternative hypothesis that there is a relationship between topic familiarity and writing performance as measured by essay score. Those who received a high score in their essay are the same students who scored high in their topic knowledge test, and the students who received a low essay score also got a low score in the topic knowledge test. This finding strengthens previous claims that "topic-relevant prior knowledge is a factor that can strongly affect writing quality and therefore must be included in a cognitive model" (Deane et al., 2008, p.19) and that topic knowledge is a major predictor of writing quality (DeGroff., 1987, Langer., 1985; McCuthen, 1986 cited in Deane et al., 2008; Tedick, 1988; Liu, 2010). This simply shows that those who possess prior topic knowledge stored in their long term have a better edge than those who do not. The usefulness of 
having more prior knowledge on a certain essay topic was attested to by the direct avowals of the respondents in the study.

As regards research question two, the study rejects the second null hypothesis and accepts the alternative hypothesis: there is a relationship between students' writing background and their essay performance. This finding validates Sasaki and Hirose' (1996) claim that L2 writing performance is characterized by one's previous writing experience and confidence in L2 writing. However, it must be noted that not all the respondents acknowledged that writing background had an effect on the success of their present writing performance--a result which was gleaned from the interview with the respondents. Some claim that even if they had poor writing background, they still obtained a high score in their diagnostic essay. This finding is understandable since writing success is an amalgamation of complex factors and cannot be attributed to writing background alone. However, there is a need to confirm this finding in future studies by identifying more specific categories that constitute writing background.

As regards research question three, the study has confirmed previous findings that the text production processes that writers engage in during the writing task impact their essay scores (Zamel, 1982; Gustilo, 2010; Chenoweth \& Hayes, 2001 and Chenoweth \& Hayes 2003; Victori, 2002). The present study, which focused only on idea generation, a subprocess of planning that proposes ideas for expression (Chenoweth \& Hayes, 2003), identified several ways in which writers may produce information to be included in the essay content. Respondents were unanimous in their interview replies regarding the role of idea generation processes in writing. Future studies will prove beneficial if more subprocesses under this subprocess of planning can be identified and a more elaborate delineation of the linguistic and non-linguistic sources in idea generation discussed by Chenoweth and Hayes (2003) can be made.

As regards research question four, the findings of the present study only partially confirmed Schoonen et al's (2003) findings on linguistic tests. While the increases in vocabulary and grammar scores significantly correlated with the increases in writing score, spelling or orthographic knowledge did not significantly correlate with essay score-a finding that needs to be re-examined in future research as the present study has no available data to explain this conflicting finding. I checked the individual spelling scores of the respondents and confirmed that there is no relationship between the two variables because many of the high essay scorers have low spelling scores; conversely, many low essay scorers have high spelling results.

\section{Conclusion}

Interpreting writing performance and the relationship between writing performance and writer variables that influence writing performance is complex because writing performance is mediated by a number of factors including cognitive, affective, and contextual factors. The present study does not provide a causal evidence between the relationships under study as the data is correlational by nature. For instance, we cannot conclude that more topic familiarity will make students become better writers. The findings of the pilot study, however, have implications for writing instruction and assessment. First, writing teachers need to bear in mind the complex interrelated variables that underlie successful writing in an academic setting. Successful writing entails 
more than just a set of skills that many teachers strain to hone. It is more of what the writers have and utilize during the whole composing process. Writing instruction needs to be anchored on a larger context, approaching writing as complex cognitive activity involving cognitive resources and utilizing processes relevant to achieving communicative goals (Deane et al., 2008). Second, writing assessment needs to develop frameworks or models informed by a thorough review of cognitive and instructional literature. Such frameworks would take into consideration the assessment of full complex abilities that are activated in writing. Such a study has been conducted by Deane et al., 2008. They have evolved a cognitively based assessment of, for, and as Learning (CBAL) designed to inform approaches to instruction and assessment.

\section{Additional file}

Additional file 1: Appendix.

Competing interest

The author has no competing interest.

Received: 6 March 2013 Accepted: 6 March 2013

Published: 2 April 2013

\section{References}

Azar, B. S. (2002). Understanding and using English grammar (3rd ed.). New York: Longman.

Almasadani, H. (2010). The relationship between Saudi EFL students' writing competence, L1 writing proficiency, and self-regulation. European Journal of Social Sciences, 16(1), 53-63.

Beale, A. (2003). English Vocabulary World List. English Vocabulary World List: English Vocabulary World List. Retrieved from http://www.manythings.org/vocabulary/lists/l/words.php?f=3esl.08.

Becker, A. (2006). A review of writing model research based on cognitive processes. In A. Horning \& A. Becker (Eds.), Revision: History, theory, and practice (pp. 25-49). Indiana, USA: Parlor Press.

Bosher, S. (1998). The composing processes of three Southeast Asian writers at the post-secondary level: An exploratory study. Journal of Second Language Writing, 7(2), 205-241.

Castro, C. D. (2005). A protocol analysis of the planning processes of Japanese writers writing in English. Tanglaw. Manila, Philippines: De La Salle University Press.

Chapman, J. A. (1992). Grammar and composition. Pensacola Christian College, USA: A Beka Book.

Chenoweth, N. A., \& Hayes, J. R. (2001). Fluency in writing. Generating text in L1 and L2. Written Communication, 18(1), 80-98.

Chenoweth, N. A., \& Hayes, J. R. (2003). The inner voice in Writing. Written Communication. Retrieved from http://wcx. sagepub.com/content/20/1/99.

Coirier, P., \& Favart, M. (2002). Ordering and structuring ideas in text: From conceptual organization to linguistic formulation. European Journal of Psychology of Education, 1(2), 157-175.

Cohen, J. (1988). Statistical power and analysis for the behavioral science. Hillsdale, NJ: Lawrence Erlbaum Associates.

Cumming, A. (1989). Writing expertise and second-language proficiency. Language Learning, 39(1), 81-141.

Cusipag, M. N., Aglaua, C. M., Balarbar, C. V., Madrunio, M. R., Miciano, R. Z., \& Mojica, L. A. (2006). Critical thinking through reading and writing. Manila: De La Salle University Press.

Deane, P., Odendahl, N., Quinlan, T., Fowles, M., Welsh, C., \& Bivens-Tatum, J. (2008). Cognitive models of writing: Writing proficiency as a complex integrated skill. Retrieved from http://www.ets.org/research/contact.html.

DeGroff, L. J. C. (1987). The influence of prior knowledge on writing, conferencing, and revising. The Elementary School Journal, 88(2), 105-118.

Devine, J., Railey, K., \& Boshoff, P. (1993). The implications of cognitive models in L1 and L2 writing. Journal of Second Language Writing, 2(3), 203-225.

Ferrari, M., Bouffard, T., \& Rainville, L. (1998). What makes a good writer? Differences in good and poor writers' selfregulation of writing. Instructional Science, $26,473-488$.

Flavel, J. H. (1979). Metacognition and cognitive monitoring. American Psychologist, 34(10), 906-911.

Flower, L., \& Hayes, J. R. (1980). The cognition of discovery: defining a rhetorical problem. College Composition and Communication, 30, 21-31.

Flower, L., \& Hayes, J. R. (1981). A cognitive process theory of writing. College Composition and Communication, 32(4), 365-387.

Galbraith, D. (2009). Cognitive models of writing. German Foreign Language Journal, 2-3, 1-23.

Gustilo, L. (2010). What you think, feel, and experience shape your writing: cognitive, affective, and contextual processes in ESL writing. The Asia-Pacific Education Researcher, 19(2), 271-285.

Gustilo, L. (2011). Linguistic features that impact essay scores: a corpus linguistic analysis of ESL writing in three proficiency levels. 3 L: Language, Literature, and Linguistics. The Southeast Asian Journal of English Language Studies, 17(1), 55-64.

Humes, A. (1983). Research on the composing process. Review of Educational Research, 53(2), 201-216.

Karagiannopoulou, E. (2006). The experience of revising for essay type examinations: Differences between first and fourth year university students. Higher Education, 51, 329-350. 
Langer, J. (1985). Children's sense of genre: A study of performance on parallel reading and writing. Written Communication, 2(2), 157-187.

Liu, X. (2010). An investigation of Chinese university EFL learners' knowledge about writing. Language Studies Working Papers, 2, 51-63.

McCutchen, D. (1986). Domain knowledge and linguistic knowledge in the development of writing ability. Journal of Memory and Lanquage, 25(4), 431-444.

McNamara, D., Crossley, S., \& McCarthy, P. (2009). Linguistic features of writing quality. Written Communication, 27(1), 57-86.

Myles, J. (2002). Second language writing and research: The writing process and error analysis in student texts. TESL-EJ, $6(2), 1-20$.

Perl, S. (1978). Five writers writing: Case studies of the composing processes of unskilled college writers (Unpublished doctoral thesis). New York: New York University.

Pianko, S. (1979). A description of the composing processes of college freshmen writers. Research in the Teaching of English, 13, 5-22.

Raimes, A. (1985). What unskilled ESL students do as they write: A classroom study of composing. TESOL Quarterly, 19 (2), 229-258.

Sasaki, M., \& Hirose, K. (1996). Explanatory variables for EFL students' expository writing. Language Learning, 46(1), 137-174.

Schoonen, R., van Gelderen, A., de Glopper, K., Hulstijn, J., Simis, A., Snellings, P., et al. (2003). First language and second language writing: The role of linguistic knowledge, speed of processing, and metacognitive knowledge. Language Learning, 53(1), 165-202

Tedick, D. (1988). The effects of topic familiarity on the writing performance of non-native writers of English at the graduate level (Unpublished doctoral dissertation). Columbus, $\mathrm{OH}$ : The Ohio State University.

Tillema, M., van den Bergh, H., Rijlaarsdam, G., \& Sanders, T. (2011). Relating self-reports of writing behavior and online task execution using a temporal model. Metacognition Learning, 6, 229-253.

Victori, M. (1995). EFL writing knowledge and strategies: an integrative study (Unpublished doctoral dissertation). Bellaterra, Spain: Universitat Autònoma de Barcelona.

Victori, M. (1997). EFL composing skills and strategies: Four case studies. RESLA, 12, 163-184.

Victori, M. (2002). An analysis of writing knowledge in EFL composing: a case study of two effective and two less effective writers. System, 27, 537-555.

Whalen, K. (1993). A strategic approach to the development of second language written discourse competency: A comparison of mother tongue and second language written production processes (Proceedings from the Congreso de homenaje a Di Pietro). Granada: Universidad de Granada.

Zhang, J. (2008). A Comprehensive review of studies on second language writing. HKBU Papers in Applied Language Studies, 12, 1-35.

Zamel, V. (1982). Writing: The process of discovering meaning. TESOL Quarterly, 16(2), 195-209.

Zhai, L. (2008). Research methods in the study of influencing factors on L2 writing performance. Canadian Social Science, 4(6).

doi:10.1186/2229-0443-3-2

Cite this article as: Gustilo: An analysis of writer's performance, resources, and idea generation processes: the case of Filipino engineering students. Language Testing in Asia 2013 3:2.

\section{Submit your manuscript to a SpringerOpen ${ }^{\circ}$ journal and benefit from:}

- Convenient online submission

Rigorous peer review

- Immediate publication on acceptance

- Open access: articles freely available online

- High visibility within the field

- Retaining the copyright to your article

Submit your next manuscript at $\boldsymbol{\nabla}$ springeropen.com 